\title{
Hubungan Antara COPD Assessment Test (CAT) Dengan Faal Paru Pada Pasien Penyakit Paru Obstruktif Kronis Di Rumah Sakit Dr. Pirngadi Medan Tahun 2018
}

\author{
Rizki Amalia Dalimunthe', Sri Rezeki Arbaningsih ${ }^{2}$ \\ ${ }^{1}$ Fakultas Kedokteran, Universitas Muhammadiyah Sumatera Utara \\ ${ }^{2}$ Bagian IImu Penyakit Paru, Fakultas Kedokteran, Universitas Muhammadiyah Sumatera Utara
}

email: rizkiad52@gmail.com

\begin{abstract}
Abstrak
Penyakit paru obstruktif kronis (PPOK) adalah penyakit inflamasi pada paru yang dapat dicegah dan diobati serta disebabkan oleh inhalasi zat-zat berbahaya dalam jangka waktu yang lama dengan karakteristik gejala persisten pada traktus respiratorius dan berkurangnya aliran udara yang terjadi akibat abnormalitas pada jalan nafas maupun alveolus. COPD Assessment Test (CAT) merupakan metode yang digunakan untuk menilai kualitas hidup dan masa eksaserbasi dari penyakit paru obstruktif kronis. Penelitian ini adalah untuk menentukan hubungan antara skor CAT dan fungsi paru pada pasien PPOK stabil. Jenis penelitian ini adalah deskriptif analitik dengan studi lintang. Subjek penelitian ini adalah pasien PPOK stabil pada bulan September - Oktober 2018, dengan total subjek 30 orang. Menggunakan tekhnik purposive sampling dan data dianalisis dengan tes spearman. Data diambil melalui pengisisan kuesioner. Hasil penelitian ini menunjukkan hubungan antara CAT dan PPOK $(p=0,01)$ dengan correlation coefficient 0,559 . Terdapat hubungan yang signifikan antara CAT dengan tes fungsi paru.
\end{abstract}

Kata Kunci: COPD Assessment Test(CAT), PPOK, Fungsi Paru

$(\mathrm{cc}) \mathrm{BY}$

This work is licensed under a Creative Commons Attribution 3.0 License.

\section{PENDAHULUAN}

Penyakit paru obstruktif kronis (PPOK) adalah penyakit inflamasi pada paru yang dapat dicegah dan diobati yang disebabkan oleh inhalasi zat-zat berbahaya dalam jangka waktu yang lama. Karakteristik dari penyakit paru obstruktif kronis adalah gejala persisten pada traktus respiratorius dan berkurangnya aliran udara yang terjadi akibat abnormalitas pada jalan nafas maupun alveolus. ${ }^{1}$

Gejala dari penyakit paru obstruktif kronis adalah adanya usaha saat bernafas, batuk kronis dan produksi sputum yang semakin banyak ${ }^{2}$

Berdasarkan World Health

Organization (WHO), 65 juta orang memiliki penyakit paru obstruktif kronis yang sedang sampai berat. Pada tahun 2015, jumlah kematian akibat PPOK lebih dari 3 juta orang, setara dengan $5 \%$ dari semua kematian secara global di dunia. Diperkirakan pada tahun 2030, PPOK menjadi penyebab kematian terbanyak yang utama ketiga ${ }^{3,4}$

Berdasarkan jurnal Lung India, jumlah kematian akibat PPOK diperkirakan lebih dari $64,7 \%$ dari 100.000 jumlah kematian pada laki-laki dan perempuan ${ }^{5}$

Di Indonesia pada tahun 2013, ditemukan bahwa penyakit paru obstruktif kronik termasuk di dalam daftar penyakit tidak menular yang prevalensinya adalah $3,7 \%$ dan lebih banyak terkena pada lakilaki. $^{6}$ 
Pada PPOK, terdapat pembesaran kelenjar mukosa bronkus, metaplasia sel goblet, inflamasi, hipertrofi otot polos pernapasan serta distorsi akibat fibrosis ${ }^{7}$

Untuk memastikan adanya hambatan aliran udara, maka perlu dilakukan pemeriksaan spirometri. Spirometri merupakan metode yang akurat dalam mengukur atau menilai adanya hambatan jalan nafas. Spirometri dapat menilai derajat keparahan dari penyakit paru obstruktif kronis. ${ }^{8}$

Terdapat metode lain yang digunakan untuk menilai kualitas hidup dan masa eksaserbasi dari penyakit paru obstruktif kronis, yaitu COPD Assessment Test (CAT). ${ }^{9}$ COPD Assessment Test (CAT) dapat menilai keadaan dari pasien pada saat kambuh maupun saat keluhan sudah berkurang. Menurut penelitian yang dilakukan tahun 2013, CAT dapat mendeteksi perubahan awal dari status kesehatan pada pasien penyakit paru obstruktif kronik. Kuesioner ini juga dapat melihat perbaikan dan memburuknya keadaan pasien yang dirawat di rumah sakit akibat eksaserbasi dari penyakit paru obstruktif kronik. ${ }^{10}$

\section{METODE PENELITIAN}

Jenis penelitian yang dilakukan bersifat deskriptif analitik dengan desain cross-sectional yang bertujuan untuk mengetahui hubungan antara COPD Assessment test (CAT) dengan faal paru pada pasien PPOK stabil

Penelitian ini dilakukan di poliklinik paru di Rumah sakit Dr. Pirngadi Medan Pirngadi Medan. Metode penarikan sampel pada penelitian ini yaitu purposive sampling.

Subjek penelitian ini adalah pasien PPOK stabil yang berjumlah 30 orang dengan kriteria inkliusi adalah (a) PPOK murni, (b) Umur lebih besar atau sama dengan 35-65 tahun, (c) Menandatangani informed Consent. Sedangkan kriteria eksklusi adalah: (a) Pasien dengan penyakit pernapasan kronik lainnya, seperti: asma bronkial, kistik fibrosis, bronkiekstasis yang berat, kanker paru, penyakit paru restriktif, riwayat TB paru, (b) Eksaserbasi PPOK karena penyakit lain, seperti: pneumonia, pneumothoraks, dan gagal jantung yang tidak dikompensasi, (c) Pasien yang membutuhkan ventilasi mekanik yang invasif maupun yang tidak invasif, (d) Tidak terdapat gangguan jiwa dan tidak terdapat keadaan yang merupakan kontraindikasi dilakukannya spirometri.

Data yang digunakan dalam penelitian ini dikumpulkan dengan menggunakan kuesioner. Data yang terkumpul dalam penelitian ini dianalisis secara univariat dan bivariat. Analisis univariat bertujuan untuk mengetahui gambaran distribusi frekuensi variabel independen (faal paru) dan variabel dependen (CAT) yang penelitian. Analisis bivariat dilakukan untuk mengetahui hubungan variabel independen dan variabel dependen. Uji statistik yang digunakan untuk membantu analisis adalah uji Spearman.

\section{HASIL PENELITIAN}

\section{Analisis Univariat}

\section{Karakteristik Responden}

Penelitian ini menggunakan 30 responden untuk menilai hubungan antara COPD Assessment Test (CAT) dengan faal paru pada pasien PPOK stabil di Rumah Sakit Dr.Pirngadi Medan

Berdasarkan tabel 1. didapatkan hasil bahwa responden berjenis kelamin perempuan hanya 1 orang $(3,3 \%)$ dan responden laki-laki memiliki jumlah terbanyak yaitu 29 orang $(96,6 \%)$. 
Tabel 1. Distribusi Frekuensi Responden Berdasarkan Jenis Kelamin

\begin{tabular}{ccc}
\hline $\begin{array}{c}\text { Jenis } \\
\text { Kelamin }\end{array}$ & $\begin{array}{c}\text { Frekuensi } \\
(\mathbf{n})\end{array}$ & $\begin{array}{c}\text { Persentase } \\
(\%)\end{array}$ \\
\hline $\begin{array}{c}\text { Perempuan } \\
\text { Laki-laki }\end{array}$ & 1 & 3,3 \\
& 29 & $96,6 \%$ \\
\hline Total & 50 & 100,0 \\
\hline
\end{tabular}

Berdasarkan tabel 2. didapatkan Kelompok usia yang paling banyak dijumpai adalah kelompok 56-60 tahun (46,6\%). Disusul oleh kelompok usia 3640 tahun sebanyak 5 orang (16,6\%), responden berusia 51-55 tahun tahun sebanyak 4 orang $(13,3 \%)$, responden berusia 61-65 tahun sebanyak 3 orang (10\%) dan responden berusia 41-45 dan 46-50 tahun masing-masing sebanyak 2 orang $(6,6 \%)$.

Tabel 2. Distribusi Frekuensi Responden Berdasarkan Usia

\begin{tabular}{ccc}
\hline Usia & Frekuensi(n) & $\begin{array}{c}\text { Persentas } \\
\mathbf{i}(\%)\end{array}$ \\
\hline $36-40$ & 5 & 16,6 \\
$41-45$ & 2 & 6,6 \\
$46-50$ & 2 & 6,6 \\
$51-55$ & 4 & 13,3 \\
$56-60$ & 14 & 46,6 \\
$61-65$ & 3 & 10 \\
\hline Total & 30 & 100 \\
\hline
\end{tabular}

Berdasarkan tabel 3. didapatkan hasil bahwa pekerjaan dari responden yang banyak adalah wiraswasta sebanyak 12 orang (40\%). Disusul dengan satpam 4 orang $(13,3 \%)$, pegawai swasta dan pegawai negeri sipil masing-masing sebanyak 3 orang $(9,9 \%)$, diikuti oleh tukang sebanyak 2 orang $(6,6 \%)$, dan kepala sekolah, ibu rumah tangga, buruh, marketing, dan pengendara angkutan umum masing-masing sebanyak 1 orang $(3,3 \%)$

\section{Distribusi Frekuensi Kategori Klasifikasi Perokok pada Pasien PPOK}

Distribusi frekuensi kategori klasifikasi perokok pada pasien PPOK yang menjadi responden pada RSUD Dr. Pirngadi Medan dapat dilihat tabel 4 .

Tabel 3. Distribusi Frekuensi Responden Berdasarkan Pekerjaan

\begin{tabular}{ccc}
\hline Pekerjaan & $\begin{array}{c}\text { Frekuensi } \\
\text { (n) }\end{array}$ & $\begin{array}{c}\text { Persentasi } \\
\text { (\%) }\end{array}$ \\
\hline Wiraswasta & 12 & 40 \\
Satpam & 4 & 13,3 \\
Kepala sekolah & 1 & 3,3 \\
Petani & 1 & 3,3 \\
Tukang & 2 & 6,6 \\
PNS & 3 & 9,9 \\
Ibu Rumah Tangga & 1 & 3,3 \\
Pegawai Swasta & 3 & 9,9 \\
Buruh & 1 & 3,3 \\
Pengendara & 1 & 3,3 \\
Angkutan Umum & & \\
Marketing & 1 & 3,3 \\
\hline Total & $\mathbf{3 0}$ & $\mathbf{1 0 0}$ \\
\hline
\end{tabular}

Tabel 4. menunjukkan bahwa, distribusi frekuensi klasifikasi derajat obstruksi dan kategori klasifikasi perokok berdasarkan Brinkman's Index yang paling banyak adalah klasifikasi derajat obstruksi sedang, dengan kategori klasifikasi perokok berdasarkan Brinkman's Index Berat sebanyak 20 orang $(66,6 \%)$. Disusul dengan distribusi frekuensi klasifikasi derajat obstruksi sedang dengan klasifikasi perokok berdasarkan Brinkman's Index sedang sebanyak 7 orang (23,3\%). Distribusi frekuensi klasifikasi derajat obstruksi berat dengan kategori klasifikasi perokok berdasarkan Brinkman's Index berat sebanyak 2 orang $(6,6 \%)$. Hal ini selaras dengan penelitian pada tahun 2010, yang menyatakan bahwa merokok dengan jangka waktu yang lama $\geq 20$ pak per 
tahun dan merokok $\geq 40$ tahun dapat menurunkan VEP1/KVP $<70 \%$. Semakin lama dan banyak jumlah batang yang dihisap tiap harinya, semakin tinggi resiko peningkatan obstruksi jalan napas.

Tabel 4. Distribusi Frekuensi Kategori Klasifikasi Perokok pada Pasien PPOK

\begin{tabular}{ccc}
\hline $\begin{array}{c}\text { Klasifikasi } \\
\text { derajat } \\
\text { obstruksi }\end{array}$ & $\begin{array}{c}\text { Kategori } \\
\text { klasifikasi } \\
\text { perokok } \\
\text { (Index } \\
\text { Brinkman) }\end{array}$ & $\begin{array}{c}\text { Jumlah } \\
\text { subjek } \\
\text { dan } \\
\text { Persentas } \\
\text { e (n dan } \\
\%)\end{array}$ \\
\hline Sedang & $\begin{array}{c}\text { Sedang }(200- \\
599)\end{array}$ & $7(23,3 \%)$ \\
& $\begin{array}{c}\text { Berat }(>600) \\
\text { Berat }\end{array}$ & $\begin{array}{c}\text { Sedang }(200- \\
599)\end{array}$ \\
& $\begin{array}{c}5(66,6 \%) \\
\text { Berat }(>600)\end{array}$ & $2(6,6 \%)$ \\
\hline
\end{tabular}

Tabel 5. Distribusi Frekuensi Jumlah Skor CAT pada Klasifikasi Derajat Obstruksi

\begin{tabular}{ccc}
\hline $\begin{array}{c}\text { Klasifikasi } \\
\text { derajat } \\
\text { obstruksi }\end{array}$ & $\begin{array}{c}\text { Skor } \\
\text { CAT }\end{array}$ & $\begin{array}{c}\text { Jumlah } \\
\text { subjek dan } \\
\text { Persentase } \\
\text { (n dan \%) }\end{array}$ \\
\hline Sedang & $0-10$ & $22(73,3 \%)$ \\
& $11-20$ & $6(20 \%)$ \\
Berat & $21-30$ & $0(0 \%)$ \\
& $>30$ & $26,6 \%)$ \\
\hline
\end{tabular}

Berdasarkan tabel 5. menunjukkan bahwa kelompok skor CAT 0-10 dengan klasifikasi derajat obstruksi sedang memiliki jumlah subjek yang terbanyak yaitu 22 orang (73,3\%). Disusul kelompok skor CAT 11-20 dengan klasifikasi derajat obstruksi sedang yaitu 6 orang (20\%), kelompok skor CAT 21-30 dengan klasifikasi derajat obstruksi berat 1 orang $(3,3 \%)$, dan kelompok skor CAT >30 dengan klasifikasi derajat obstruksi berat 1 orang $(3,3 \%)$.
Dalam analisis bivariat peneliti menggunakan uji statistik dengan uji Spearman. Peneliti ingin mengetahui ada atau tidaknya hubungan hubungan antara COPD Assessment test (CAT) dengan faal paru pada pasien PPOK stabil di Rumah Sakit Dr. Pirngadi Medan. Tingkat kemaknaan yang dipakai adalah $\alpha=0,05$. Variabel dikatakan berhubungan secara signifikan apabila nilai $p<0,05$.

Tabel 6. Hubungan antara COPD Assessment test (CAT) dengan faal paru pada pasien PPOK stabil

\begin{tabular}{|c|c|c|c|c|c|c|c|}
\hline \multirow{2}{*}{$\begin{array}{l}\text { Tingkatan } \\
\text { Faal Paru }\end{array}$} & \multicolumn{4}{|c|}{ Kuesioner CAT } & \multirow[t]{2}{*}{ Total } & \multirow[t]{2}{*}{$\mathbf{p}$} & \multirow[t]{2}{*}{$\mathbf{r}$} \\
\hline & Rendah & Sedang & Tinggi & $\begin{array}{l}\text { Sangat } \\
\text { Tinggi }\end{array}$ & & & \\
\hline Sedang & 22 & 6 & 0 & 0 & 28 & & \\
\hline Berat & 0 & 0 & 1 & 1 & 2 & 0,001 & 0,559 \\
\hline Total & 22 & 6 & 1 & 1 & 30 & & \\
\hline
\end{tabular}

Uji pada tabel 6. menggunakan uji Spearman untuk melihat hubungan variabel hubungan antara COPD Assessment Test dengan faal paru maka diperoleh hasil nilai $p$-value $=0,001$ yang menunjukkan terdapatnya hubungan yang bermakna antara COPD Assessment Test dengan faal paru karena nilai $p$ yang didapatkan $<0,05$. Nilai koefisien korelasi (r) dari penelitian ini adalah 0,559 yang menunjukkan kekuatan korelasi antara COPD Assesssment Test dengan faal paru adalah sedang.

\section{PEMBAHASAN}

Pada penelitian ini didapatkan hasil bahwa responden berjenis kelamin perempuan hanya 1 orang $(3,3 \%)$ dan responden laki-laki memiliki jumlah terbanyak yaitu 29 orang $(96,6 \%)$. Studi ini juga sesuai dengan studi yang dilakukan pada tahun 2018, ditemukan bahwa prevalensi pasien PPOK dengan jenis kelamin laki-laki lebih tinggi dibandingkan jenis kelamin perempuan ${ }^{11}$ 
Hal ini dapat terjadi dikarenakan merokok. Tetapi diperkirakan $20 \%$ dari pasien dengan PPOK tidak berhubungan dengan kebiasaan merokok. ${ }^{12}$ Terdapat faktor risiko lainnya yang dapat menyebabkan PPOK seperti respons yang berlebihan dan sensitivitas yang abnormal terhadap zat-zat yang dihirup, atau paparan zat seperti perokok pasif, gas biomassa, debu, gas-gas yang terdapat pada tempat bekerja dan polusi udara. ${ }^{13}$

Kelompok usia yang paling banyak dijumpai adalah kelompok 56-60 tahun (46,6\%). Disusul oleh kelompok usia 3640 tahun sebanyak 5 orang (16,6\%), responden berusia 51-55 tahun tahun sebanyak 4 orang (13,3\%), responden berusia 61-65 tahun sebanyak 3 orang (10\%) dan responden berusia 41-45 dan 46-50 tahun masing-masing sebanyak 2 orang $(6,6 \%)$. Hal ini sejalan dengan penelitian National Institute of Health pada tahun 2014, yang menyatakan bahwa prevalensi PPOK lebih banyak pada kelompok umur 55-70 tahun. ${ }^{14}$ Berdasarkan penelitian yang dilakukan tahun 2013 di Italia, alasan mengapa PPOK merupakan penyakit yang lebih banyak menyerang orang tua adalah efek kumulatif dari rokok dan polutan lainnya. Pemendekan telomer juga berhubungan dengan proses penuaan. Disfungsi telomer dan percepatan pemendekan telomer merupakan penyebab dari terganggunya sel-sel endotelial yang termasuk pada proses aterosklerosis. Pada pasien usia tua dengan PPOK kapasitas vital paru akan menurun sebanyak $30 \mathrm{~mL}$ per tahunnya. Orang dengan proses penuaan yang normal, kapasitas paru akan berkurang sebanyak 10-20 mL per tahunnya. Volume residu akan meningkat pada proses penuaan yang normal dan juga pada pasien yang tua dengan PPOK. Rekoil dari paru, pembersihan mukosiliar, imunitas mukosa, dan fungsi vaskular akan mulai berkurang pada proses penuaan, dan akan lebih banyak berkurang pada pasien dengan PPOK. $^{15}$

Pekerjaan dari responden yang banyak adalah wiraswasta sebanyak 12 orang (40\%). Disusul dengan satpam 4 orang $(13,3 \%)$, pegawai swasta dan pegawai negeri sipil masing-masing sebanyak 3 orang $(9,9 \%)$, diikuti oleh tukang sebanyak 2 orang (6,6\%), dan kepala sekolah, ibu rumah tangga, buruh, marketing, dan pengendara angkutan umum masing-masing sebanyak 1 orang $(3,3 \%)$. Ditemukan bahwa terdapat hubungan antara paparan zat-zat kimia saat di tempat kerja, sekitar $10-15 \%$ dari total penyebab PPOK. Prevalensi PPOK pada pekerja terdapat sekitar $30 \%$ pada populasi usai bekerja. Pekerjaan yang dapat menjadi faktor risiko terhadap terjadinya PPOK adalah pekerja bangunan, promotor produk, pembantu rumah tangga, petani, koki, pekerja pabrik, pekerja yang bersinggungan dengan besi dan baja setiap harinya, operator mesin, mekanik dan reparasi elektronik, pekerja Stasiun Pengisian Bahan Bakar Umum, pekerja yang bersinggungan dengan karet, plastik, kulit, dan silikon, pekerja pada pabrik cat dan tekstil, supir, pelayan rumah makan, dan pekerja kayu. Hal ini selaras dengan responden dari penelitian ini yang memiliki pekerjaan yang sesuai dengan jurnal yang penelitiannya dilaksanakan di United Kingdom pada tahun 2015. ${ }^{16}$

Distribusi frekuensi klasifikasi derajat obstruksi dan kategori klasifikasi perokok berdasarkan Brinkman's Index yang paling banyak adalah klasifikasi derajat obstruksi sedang, dengan kategori klasifikasi perokok berdasarkan Brinkman's Index Berat sebanyak 20 orang $(66,6 \%)$. Disusul dengan distribusi frekuensi klasifikasi derajat obstruksi 
sedang dengan klasifikasi perokok berdasarkan Brinkman's Index sedang sebanyak 7 orang (23,3\%). Distribusi frekuensi klasifikasi derajat obstruksi berat dengan kategori klasifikasi perokok berdasarkan Brinkman's Index berat sebanyak 2 orang $(6,6 \%)$. Hal ini selaras dengan penelitian pada tahun 2010, yang menyatakan bahwa merokok dengan jangka waktu yang lama $\geq 20$ pak per tahun dan merokok $\geq 40$ tahun dapat menurunkan VEP1/KVP $<70 \%$. Semakin lama dan banyak jumlah batang yang dihisap tiap harinya, semakin tinggi resiko peningkatan obstruksi jalan napas. ${ }^{17}$

Kelompok skor CAT 0-10 dengan klasifikasi derajat obstruksi sedang memiliki jumlah subjek yang terbanyak yaitu 22 orang (73,3\%). Disusul kelompok skor CAT 11-20 dengan klasifikasi derajat obstruksi sedang yaitu 6 orang (20\%), kelompok skor CAT 21-30 dengan klasifikasi derajat obstruksi berat 1 orang $(3,3 \%)$, dan kelompok skor CAT $>30$ dengan klasifikasi derajat obstruksi berat 1 orang $(3,3 \%)$. Hal ini sesuai dengan penelitian yang dilakukan di Jakarta pada tahun 2012, sebaran skor CAT yang terbanyak adalah skor CAT $<10$ yaitu 39 orang $(63,9 \%)$ dan sebaran skor CAT $\geq 10$ adalah 22 orang $(36,1 \%) .{ }^{18} \mathrm{Hal}$ ini selaras dengan penelitian yang dilakukan pada tahun 2014 yang menyatakan bahwa kategori PPOK yang terbanyak klasifikasi spirometri dengan GOLD 1-2. ${ }^{19}$ Klasifikasi spirometri GOLD 2 hanya ditemukan pada tingkatan PPOK A dan B. ${ }^{1}$

$$
\text { Hubungan antara COPD }
$$

Assessment Test (CAT) dengan faal paru pada pasien PPOK stabil, hasil analisis dari uji statistik Spearman didapatkan hasil nilai $p=0,026$ yang menunjukkan angka yang signifikan karena nilai $p$ lebih kecil dibandingkan dengan taraf signifikan $(\alpha)=5 \%(0,05)$, artinya ada hubungan yang bermakna antara COPD Assessment
Test (CAT) dengan faal paru pada pasien PPOK stabil Rumah Sakit Dr. Pirngadi Medan. Hal ini selaras dengan penelitian yang dilakukan pada tahun 2012, yang meneliti hubungan antara COPD Assessment Test (CAT), dimana hubungannya dengan faal paru memiliki korelasi yang kuat $(p=0.001)$. Hal ini dapat menjelaskan bahwa semakin tinggi skor CAT maka semakin rendah pula faal paru pada pasien $\mathrm{PPOK}^{20}$

\section{KESIMPULAN}

Terdapat hubungan yang signifikan antara COPD Assessment Test (CAT) dengan faal paru pada pasien PPOK stabil di Rumah Sakit Dr. Pirngadi Medan, dengan nilai $p$ sebesar $0,001(p<0,05)$.

\section{REFERENSI}

1. Global Initiatives For Chronic Obstructive Lung Disease. Global Strategy For Diagnosis, Management, And Prevention Of Chronic Obstructive Pulmonary Disease. 2018.

2. Japanese T, Society R. Guidelines for the Diagnosis and Treatment of COPD, 3rd edition [Pocket Guide]. 2010.

3. Diaz-Guzman E, Mannino DM. Epidemiology and prevalence of chronic obstructive pulmonary disease. Clin Chest Med. 2014;35(1):7-16.

Sana A, Somda SMA, Meda N, Bouland C. Chronic obstructive pulmonary disease associated with biomass fuel use in women: a systematic review and meta-analysis. BMJ Open Respir Res. 2018;5(1):e000246.

5. Koul P. Chronic obstructive pulmonary disease: Indian guidelines and the road ahead. Lung India. 2013;30(3):175.

6. Badan Penelitian dan Pengembangan Kesehatan. Riset Kesehatan Dasar (RISKESDAS) 2013. Lap Nas 2013. 2013:1-384.

7. Putra W, Artika IDM. Diagnosis dan Tatalaksana Penyakit Paru Obstruktif Kronis. IImu Penyakit Dalam FK UNUD/RSUP Sanglah Denpasar. 2007:1-16.

8. National Clinical Guideline Centre. 
Chronic obstructive pulmonary disease: Management of chronic obstructive disease in adults in primary and secondary care. $R$ Coll Physicians London. 2004;Update 20:673.Sanglah Denpasar. 2007:1-16.

9. Ringbaek T, Martinez G, Lange P. A comparison of the assessment of quality of life with CAT, CCQ, and SGRQ in COPD patients participating in pulmonary rehabilitation. COPD $J$ Chronic Obstr Pulm Dis. 2012;9(1):1215.

10. Feliz-rodriguez D, Zudaire S, Carpio C, et al. Evolution of the COPD Assessment Test score during chronic obstructive pulmonary disease exacerbations: Determinants and prognostic value. 2013;20(5):92-97.

11. Altman P, Fogel R, Sayre T, Ntzani EE, Evangelou E. Gender-specific estimates of COPD prevalence: a systematic review and meta-analysis. 2018:1507-1514.

12. Lamprecht B, Mcburnie MA, Vollmer WM. CHEST COPD in Never Smokers Results From the Population-Based Burden of Obstructive Lung Disease Study. 2011.

13. Mannino DM, Buist AS. Global burden of COPD : risk factors, prevalence, and future trends. Lancet. 2007;370(9589):765-773.

14. Med JOE. HHS Public Access. 2015;56(10):1088-1093.

15. Antonelli R, Scarlata S, Pennazza G, Santonico M, Pedone C. European Journal of Internal Medicine Chronic Obstructive Pulmonary Disease in the elderly. Eur J Intern Med. 2013.

16. Fishwick D, Sen D, Barber C, et al. Occupational chronic obstructive pulmonary disease : a standard of care. 2015:270-282.

17. Ohar JA, Sadeghnejad A, Meyers DA. Do Symptoms Predict COPD in Smokers. 2010:1345-1353.

18. Mokoagow MI, Uyainah A, Subardi S, Rumende CM, Amin Z. Peran Skor COPD Aseessment Test ( CAT ) sebagai Prediktor Kejadian Eksaserbasi Akut Penyakit Paru Obstruktif Kronik pada Jemaah Haji Provinsi DKI Jakarta Tahun 2012. 2014;1(2).

19. Papaioannou M, Pitsiou G, Manika K, et al. COPD assessment test: A simple tool to evaluate disease severity and response to treatment. COPD $J$ Chronic Obstr Pulm Dis. 2014;11(5):489-495.

doi:10.3109/15412555.2014.898034

20. Ghobadi H, Sadeghieh S, Lari M. The Relationship between COPD Assessment Test ( CAT ) Scores and Severity of Airflow Obstruction in Stable COPD Patients. 2012;i(2):22-26 
